\title{
Managerial Compensation and the Market Reaction to Bank Loans
}

\author{
Andres Almazan \\ University of Texas \\ Javier Suarez \\ CEMFI and CEPR
}

Working Paper No. 0103

January 2001

We would like to thank Arnoud Boot, Douglas Diamond, Gary Gorton, Denis Gromb, Charles Hadlock, Narasimhan Jegadeesh, Claudio Michelacci, Jorge Padilla, George Pennachi, Ramesh Rao, Sheridan Titman, an anonymous referee, and seminar participants at the Western Finance Association Meetings, the European Summer Symposium in Financial Markets, the University of Illinois, and the University of Texas for helpful comments to previous versions of this paper. The remaining errors are our sole responsibility. (Email addresses: suarez@cemfi.es, andres.almazan@bus.utexas.edu).

CEMFI, Casado del Alisal 5, 28014 Madrid, Spain.

www.cemfi.es 


\begin{abstract}
This paper considers why a manager would choose to submit himself to the discipline of bank monitoring. This issue is analyzed within the context of a model where the manager enjoys private benefits, which can be restricted by the monitor, and is optimally compensated by shareholders. Within this setting, we find that managers will submit to monitoring when they receive favorable private information. This result is consistent with event study evidence that suggests that the market has a favorable view of financing choices that increase monitoring.
\end{abstract}

JEL classification: G32, G34.

Keywords: monitoring, managerial compensation, optimal contracts, banks. 


\section{Introduction}

Previous research has analyzed the monitoring role of banks in entrepreneurial models where firms are managed by their owners. ${ }^{1}$ In these models, entrepreneurs relinquish control in favor of a monitor whenever monitoring produces a net gain in firm value. ${ }^{2}$ However in public corporations, where ownership and control are separated, a conflict of interest emerges: the cost of bank monitoring falls largely on management, while the potential gain in value accrues, in principle, to shareholders.

In this paper we examine the case in which shareholders cannot directly control a firm's investing and financing decisions but can offer incentive compensation to affect these choices. We characterize the optimal managerial compensation contract and explain why some firms use bank financing while others do not, why the choice of bank financing tends to raise the firm's stock price, and how these price effects can be used by shareholders to induce optimal financing decisions.

The managers in our model have a tendency to extract private benefits that hurt shareholders. This tendency is affected by the manager's compensation contract and can also be imperfectly controlled by bank monitoring. In our setting, banks reduce the size of the manager's private benefits, i.e., managers' temptations to misbehave, and so complement the use of incentive compensation by reducing its cost.

The cost of providing a compensation package that induces the manager to take less private benefits also depends on firm profitability, which is not known before the compensation contract is written. We characterize profitability as the firm's probability of success and consider a firm that can turn out to be one of two types, a type with a high probability of success and a type with a low probability of success. If

\footnotetext{
${ }^{1}$ See, for example, Diamond (1984), Rajan (1992), and Holmstrom and Tirole (1997).

${ }^{2}$ Say, by inducing more efficient investment and liquidation decisions and/or by increasing the firm's debt capacity.
} 
the firm turns out to be the high type, then a lower level of incentive pay can be used to induce the manager to submit to bank monitoring and forsake inefficient private benefits. However, if the firm turns out to be the low type, then a higher level of incentive pay must be used to induce such a desirable behavior.

Because firm type is not initially known, shareholders cannot offer compensation contracts that are contingent on whether or not the firm turns out to be the high or low type, therefore, to induce the manager to behave when the firm turns out to be low shareholders would have to substantially overpay the manager when the firm turns out to be high. However, as we show, shareholders may be able to induce the high and low type firms to separate by making the manager's compensation to depend on whether or not he chooses to be monitored by a bank. In particular, we show that two regimes (i.e., combinations of financing and incentive contracts) may emerge depending on parameters. In what we will call the separating regime, shareholders offer a contract that induces only high profitability firms to use bank financing and incentive pay. In the pooling regime, all firms are attracted to bank financing. In this regime, a higher level of incentive pay is employed which generates additional rents to the managers of high profitability firms.

The separating regime can be characterized by an (endogenous) association between the firms' unobservable profitability, bank monitoring, and incentive pay which makes the use of bank financing work as a signal of high profitability. Thus, this association provides a theoretical rationale for James (1987) result that the announcement of a bank loan agreement produces positive abnormal returns on the borrower's stock. ${ }^{3}$ We show that the valuation effects that follow the announcement of financing

\footnotetext{
${ }^{3}$ Lummer and McConnell (1989), as well as Best and Zhang (1993), argue that the positive market reaction documented by James (1987) only applies to loan renewals. However, with a revised empirical definition of new loans, Billet, Flannery, and Garfinkel (1995) find no significant differences between initiations and renewals; the same applies to Slovin, Johnson, and Glascock (1992) and Hadlock and James (2000).
} 
choices allow an intuitive implementation of the optimal contract using market-based compensation.

Our analysis offers predictions both on the size and the direction of the market reaction to the announcement of financing choices as well as on the cross-sectional determinants of these choices. Additionally, our results raise novel predictions regarding the links between incentive compensation and financing sources. For instance, it is suggested that firms that use bank financing will tend to be characterized by larger pay-performance sensitivities.

This paper combines ingredients from two strands of the banking literature. As in the screening models (e.g., Boyd and Prescott (1986) and Diamond (1991)), a successful credit agreement is good news about the firm's profitability. However our argument does not rely on banks' advantage in evaluating firms' profitability but on the fact that banks perform a monitoring function that managers dislike. This feature brings us close to the monitoring models (e.g., Rajan (1992), Diamond (1993), and Holmstrom and Tirole (1997)) which emphasize the role of banks in alleviating moral hazard problems through monitoring. ${ }^{4}$ Part of our contribution is to show that adding unobservable heterogeneity (private information) to models which had reasonably succeeded in identifying the observable determinants of the use of bank loans allows them to also accommodate the evidence on bank loan announcements. ${ }^{5}$

Finally, it is worth noting that one can apply the logic of our analysis to other cases where managers voluntarily submit to increased monitoring. Examples include

\footnotetext{
${ }^{4}$ A third strand of the literature (e.g., Detragiache (1994) and Gorton and Kahn (2000)) focuses on the role of banks in debt renegotiations and financial restructuring following episodes of financial distress. These papers offer implications consistent with the announcement effects associated with loan renewals among financially troubled firms. Our theory points out to a mechanism whereby the announcement effects may also occur following initiations and among financially sound publicly traded firms.

${ }^{5}$ For a recent empirical study on the observable determinants of the choice between market and bank financing, see Cantillo and Wright (2000).
} 
managerial proposals to change governance, accounting, auditing or internal organization whose main consequence is a reduction in the private benefits that the managers might obtain by deviating from value maximization. Our results provide insights about the type of managerial compensation contracts that one can use to induce these changes and clarify the circumstances in which their announcement is likely to produce stock price responses.

The paper is organized as follows. In Section 2 we describe the model. In Section 3 we analyze the optimal contracting problem. Section 4 describes the two different regimes that may arise and the factors that determine the prevalence o $f$ one or the other. In Section 5 we examine the valuation effects of financing choices. Section 6 discusses the implementation of the optimal contract through market-based compensation. We discuss the main implications of our analysis in Section 7. Section 8 concludes the paper.

\section{The Model}

\subsection{Agents, technology, and modes of financing}

We consider a publicly traded firm that operates in a risk neutral economy in which the market rate of return is normalized to zero. The firm is owned by small shareholders and run by a manager. Shareholders and the manager maximize their lifetime pecuniary and non-pecuniary income. The manager has no wealth, is protected by limited liability, and has a zero reservation level of utility.

The firm has a project which requires an initial investment $I$ and yields a terminal cash flow $x=R$ if it succeeds and $x=0$ otherwise. ${ }^{6}$ The probability of success depends partly on the project's type $\theta$, which identifies whether its profitability is

\footnotetext{
${ }^{6}$ Assuming that the project yields no cash flow in case of failure implies no loss of generality. We could have instead assumed a cash flow $k+R$ if it succeeds and $k$ otherwise.
} 
high $\left(\theta=\theta_{H}\right)$ or low $\left(\theta=\theta_{L}\right)$, and partly on the manager's "effort" decision $e$, which identifies whether the manager is diligent $(e=1)$ or extracts private benefits from the project $(e=0)$. Specifically, the distribution of terminal cash flow is

$$
x=\left\{\begin{array}{l}
R \quad \text { with probability } \theta+\Delta e, \\
0 \quad \text { with probability } 1-\theta-\Delta e,
\end{array}\right.
$$

where

$$
0<\Delta<1-\theta_{H}<1-\theta_{L}<1
$$

Thus managerial effort (choosing $e=1$ rather than $e=0$ ) produces an expected cash flow gain of $\Delta R$.

We assume, however, that the manager's effort choice is subject to a trade-off since by choosing $e=0$ he can extract some private benefits $C_{f}$ from the project, where $f$ identifies whether the project is financed by the market $(f=m)$ or by a bank $(f=b)$. In this respect, we follow the standard view that banks can exert tighter control and better monitoring of managerial discretion than smaller and more dispersed market investors. $^{7}$ Specifically, borrowing from Holmstrom and Tirole (1997), we assume that

$$
C_{b}<C_{m}
$$

which captures the idea that bank monitoring reduces the ability of the manager to extract private benefits from the firm.

\subsection{Efficiency and viability}

We assume that, under any of the available modes of finance, the effort decision that maximizes the project's total return (expected cash flow plus private benefits)

\footnotetext{
${ }^{7}$ This view is consistent with the evidence that covenants in private financing arrangements, especially bank loans, are typically more abundant and restrictive than in public security issues (see Smith and Warner (1979) and Gilson and Warner (1997)). It is also consistent with the wisdom that some features of bank financing, such as the explicit or implicit conditions governing the renewal of revolving loans and credit lines, impose effective discipline on managerial behavior (see Repullo and Suarez (1998)).
} 
is $e=1$, that is,

$$
\Delta R>C_{m}
$$

We also assume that, even with the lowest profitability type and the least favorable effort decision, the project is viable, that is,

$$
\theta_{L} R>I
$$

\subsection{Information and contracting}

The project's profitability type $\theta$ is $\theta_{L}$ with probability $\mu$ and $\theta_{H}$ with probability $1-\mu$. When the manager is hired, $\theta$ is still uncertain. Once in charge, he privately observes $\theta$. Afterwards, he decides on both the financing mode $f$, which is publicly observable, and the effort $e$, which is not. The cash-flow $x$, once it realizes, is also publicly observable. Hence the model features an asymmetry of information related to $\theta$ and an incentive problem related to $f$ and $e$. To cope with these problems, shareholders offer the manager a contract that maximizes their expected income subject to the relevant participation and incentive compatibility constraints. This contract may make the manager's compensation contingent on the observable variables $f$ and $x .^{8}$

Notice that, consistent with the discretion that managers enjoy in most publicly traded companies, we have assumed that the manager cannot be obliged to use a particular mode of financing. Once in charge, the manager will choose $f$ in order to maximize his own expected income (monetary rewards plus private benefits). ${ }^{9}$ Yet, if feasible, shareholders would surely benefit from abolishing the manager's discretion

\footnotetext{
${ }^{8}$ There is no theoretical reason to rule out the contingency on $f$. Nevertheless, since it may seem somewhat counterfactual, we will show in Section 6 that the optimal contract can be implemented using a compensation scheme based exclusively on stock market performance.

${ }^{9}$ Technically, the model is related to Sappington (1983) who analyzes a principal-agent problem in which there are ex-post limits to the maximum penalty that can be imposed on a risk neutral agent.
} 
on $f$ and imposing the use of bank financing, since this would reduce the manager's temptation to extract private benefits from the firm. ${ }^{10}$

\subsection{Sequence of events}

We can briefly review the timing of events in the model by distinguishing the following four dates:

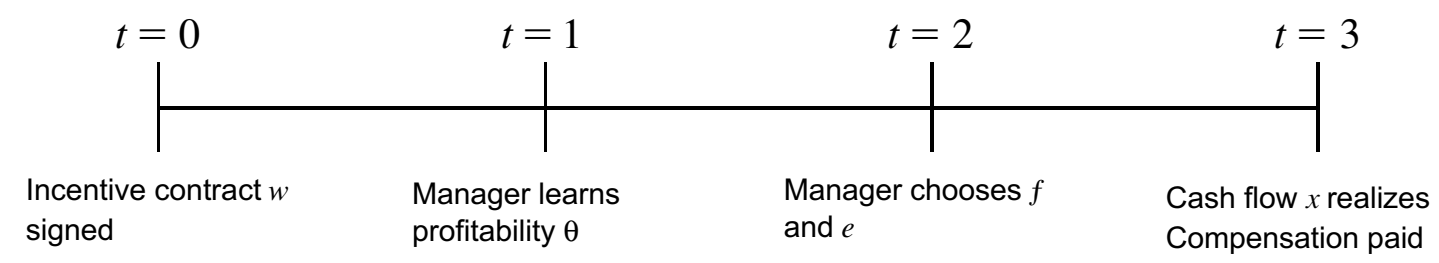

Figure 1. The sequence of events

At $t=0$ the shareholders offer an incentive contract to the manager. At $t=1$ the manager privately learns the profitability type $\theta$. At $t=2$ the manager chooses the mode of finance $f$ and his effort $e$. At $t=3$ the project's cash flow $x$ realizes and the incentive contract payments are enforced.

\section{The Manager's Contract}

In this section we characterize the optimal managerial contract. We show that such contract may correspond to different financial regimes, that is, different associations between project types, modes of financing, and compensation schemes. Later sections will examine the determinants of the occurrence of each equilibrium regime, the

\footnotetext{
${ }^{10}$ Zwiebel (1996) and Novaes and Zingales (1997) are other examples in the literature where managerial discretion over capital structure decisions can be harmful to shareholders. One could think in modifications of our model in which, in some states of the world, both shareholders and the manager prefer market financing to bank financing. In such a case it could be suboptimal to force the manager to always use bank financing. Aghion and Tirole (1997) present a model of managerial delegation along these lines.
} 
associated valuation effects, and the possibility of using market-based compensation to implement the optimal contract.

\subsection{The problem}

Shareholders offer the manager a contract that maximizes the ex ante value of the firm net of the cost of managerial compensation. By virtue of the Revelation Principle (Myerson (1979)), we can characterize such a contract restricting our attention to direct mechanisms whereby the manager, after observing the project's type $\theta$, is induced to truthfully reveal it through an announcement $z \in\left\{\theta_{L}, \theta_{H}\right\}$. Formally, this announcement appears, together with the financing mode $f$ and the effort $e$, in the triplet $(z, f, e)$ that describes the manager's action. Accordingly, a contract consists of an intended action $a(\theta)=(\theta, f(\theta), e(\theta))$ for each type $\theta$ and a compensation scheme

$$
w=\left\{\left(w_{0}(z, f), w_{R}(z, f)\right), \text { for } z=\theta_{L}, \theta_{H} \text { and } f=m, b\right\}
$$

that specifies some non-negative rewards $w_{x}(z, f)$ contingent on the announced type $z$, the chosen financing mode $f$, and the realization of $x .^{11}$

The optimal contract solves:

$$
\begin{array}{lll}
\max _{\substack{\text { max }\\
}}\left\{a\left(\theta_{j}\right)\right\}_{j=L, H} & \mu V\left(a\left(\theta_{L}\right), w ; \theta_{L}\right)+(1-\mu) V\left(a\left(\theta_{H}\right), w ; \theta_{H}\right) \\
\text { s.t. } & U\left(a\left(\theta_{L}\right), w ; \theta_{L}\right) \geq U\left(a, w ; \theta_{L}\right) \text { for all } a \\
& U\left(a\left(\theta_{H}\right), w ; \theta_{H}\right) \geq U\left(a, w ; \theta_{H}\right) \text { for all } a
\end{array}
$$

where

$$
V(a, w ; \theta) \equiv(\theta+\Delta e)\left(R-w_{R}(z, f)\right)-(1-\theta-\Delta e) w_{0}(z, f)
$$

is the value of type- $\theta$ firm to its shareholders under action $a$ and the compensation

\footnotetext{
${ }^{11}$ We assume that even with $x=0$ the manager can receive positive compensation. The firm could fulfill that commitment by "saving funds" before the realization of $x$ occurs.
} 
scheme $w$, and

$$
U(a, w ; \theta) \equiv(\theta+\Delta e) w_{R}(z, f)+(1-\theta-\Delta e) w_{0}(z, f)+(1-e) C_{f}
$$

is the manager's expected utility (monetary rewards plus private benefits) in a type- $\theta$ firm under action $a$ and the compensation scheme $w$. The constraints of this problem are the self-selection or incentive compatibility conditions required to induce the manager to follow $a(\theta)$ under each $\theta$.

Note that the manager's participation constraints have been ignored since they are trivially satisfied. In particular, the manager's reservation utility is zero but, given the non-negativity of $w$, he can always guarantee himself an expected utility (in private benefits) of at least $C_{m}>0$ by just choosing $(f, e)=(m, 0)$.

\subsection{The solution}

Conditional on self-selection, each type has four possible pairs of actions $(f, e) \in$ $\{m, b\} \times\{0,1\}$. Hence, the two types produce $4^{2}=16$ possible combinations of actions, $\left\{\left(f\left(\theta_{L}\right), e\left(\theta_{L}\right)\right),\left(f\left(\theta_{H}\right), e\left(\theta_{H}\right)\right)\right\}$. Each of these combinations will be called an allocation in order to signify that, once such combination is fixed, the firm's surplus under each $\theta$ is also fixed so the compensation scheme $w$ only affects the distribution of such a surplus between shareholders and the manager. ${ }^{12}$ For future reference, Table 1 enumerates all possible allocations.

\footnotetext{
${ }^{12}$ Note that $V(a, w ; \theta)+U(a, w ; \theta)=(\theta+\Delta) R+(1-e) C_{f}$.
} 
Table 1

Possible allocations

\begin{tabular}{ccc|c|c|c|}
\multicolumn{5}{c}{$\left(f\left(\theta_{H}\right), e\left(\theta_{H}\right)\right)$} \\
& & $(m, 0)$ & $(m, 1)$ & $(b, 0)$ & $(b, 1)$ \\
\cline { 3 - 6 }$\left(f\left(\theta_{L}\right), e\left(\theta_{L}\right)\right)$ & $(m, 0)$ & $\mathrm{A} 1$ & $\mathrm{~A} 2$ & $\mathrm{~A} 3$ & $\mathrm{~A} 4$ \\
\cline { 3 - 6 } & $(m, 1)$ & $\mathrm{A} 5$ & $\mathrm{~A} 6$ & $\mathrm{~A} 7$ & $\mathrm{~A} 8$ \\
\cline { 3 - 6 } & $(b, 0)$ & $\mathrm{A} 9$ & $\mathrm{~A} 10$ & $\mathrm{~A} 11$ & $\mathrm{~A} 12$ \\
\cline { 3 - 6 } & $(b, 1)$ & $\mathrm{A} 13$ & $\mathrm{~A} 14$ & $\mathrm{~A} 15$ & $\mathrm{~A} 16$ \\
\cline { 3 - 6 } & & & & &
\end{tabular}

\subsubsection{Candidate allocations}

Instead of exploring the implementation and the ex ante shareholder value of each allocation, we provide some results that reduce the number of potentially optimal allocations to just three. The first result refers to the requirements of incentive compatibility under a given financing mode. All proofs are in the Appendix.

Proposition 1 If a compensation scheme induces the financing choice $f(\theta)$ under project type $\theta$, then a necessary and sufficient condition for inducing $e(\theta)=1$ is

$$
w_{R}(\theta, f(\theta))-w_{0}(\theta, f(\theta)) \geq \frac{C_{f(\theta)}}{\Delta} .
$$

This proposition establishes the minimum incremental reward for success that compensation schemes associated with a given financing mode must offer in order to induce the manager to be diligent. In particular, the incremental reward for success should be such that the gain in compensation that the manager obtains by choosing $e=1$ exceeds the private benefits that the manager could have extracted by choosing $e=0$.

Proposition 2 Allocations in which bank financing are associated with low powered incentives, i.e., $(f(\theta), e(\theta))=(b, 0)$ for some $\theta$, or market financing with high powered incentives, i.e., $(f(\theta), e(\theta))=(m, 1)$ for some $\theta$, are suboptimal. 
This result excludes all allocations in rows 2 and 3 and columns 2 and 3 of Table 1, i.e., A2, A3, A5-A8, A9-A12, A14 and A15. It establishes the association of bank financing with high powered incentives and of market financing with low powered incentives. These associations reflect that bank monitoring is advantageous for the implementation of $e=1$, but disadvantageous for inducing $e=0$. Reducing the private benefits that the manager would obtain choosing $e=0$ makes $(f, e)=(b, 1)$ cheaper to implement than $(f, e)=(m, 1)$. Conversely, since the manager can always get $C_{m}$ with $(f, e)=(m, 0)$, trying to implement $(f, e)=(b, 0)$ instead would oblige shareholders to pecuniarily compensate the manager (out of a non-larger expected cash flow) for the dissipated private benefits, i.e., $C_{m}-C_{b}$.

Proposition 3 Allocations in which low profitability projects receive high powered incentives, $e\left(\theta_{L}\right)=1$, while high profitability projects receive low powered incentives, $e\left(\theta_{H}\right)=0$, are suboptimal.

This result excludes A13, as well as A5, A7, and A15 that were already excluded by Proposition 2. It establishes that a low profitability project will never be associated with higher powered incentives than a high profitability project, i.e., $e\left(\theta_{L}\right) \leq e\left(\theta_{H}\right)$. This is because, for a given $e$, the larger $\theta$ is, the more likely a project is to succeed and, thus, the more rewarding is a contract that offers a bonus in case of success. Hence the participation of a $\theta_{H}$ manager in a high powered contract is always easier to achieve than that of a $\theta_{L}$ manager.

The joint consideration of Propositions 2 and 3 reveals an association between incentive pay, bank monitoring, and high profitability projects. Importantly this association does not come from any assumed technological complementarity between bank financing and the high profitability project since, as it is clear from (1) and (3), neither the marginal effect of $e$ on cash flows nor the effects of $f$ on the manager's 
potential private benefits depend on $\theta$. The association comes from the interactions between the private information problem and the moral hazard problem that emerge in the design of the optimal contract. Therefore, we are left with three possibly optimal allocations: the market-market allocation or $m m$ (A1), the market-bank allocation or $m b(\mathrm{~A} 4)$, and the bank-bank allocation or bb (A16).

\subsubsection{Implementing the candidate allocations}

To simplify the presentation we will focus on the case in which, even with a high profitability project, inducing the manager to choose bank financing generates some extra compensation cost (beyond what would be required to implement $e=1$ under a non-discretionary $f$ ). This case occurs when $C_{m}$ is sufficiently larger than $C_{b}$, specifically when

$$
C_{m}>\left(\theta_{H}+\Delta\right) \frac{C_{b}}{\Delta}
$$

which strengthens $(3) .{ }^{13}$

Assuming (10), we will first characterize the minimum cost compensation schemes $w^{m b}$ and $w^{b b}$ that implement $m b$ and $b b$, respectively, and then establish the dominance of $m b$ over $m m .^{14}$ The characterized schemes share three features. First, their rewards $w_{x}(z, f)$ do not vary with $z$, that is, the implementation of $m b$ and $b b$ does not require rewards that explicitly depend on the announcement of the project's type. ${ }^{15}$ Type

\footnotetext{
${ }^{13}$ To obtain (10), suppose that $f\left(\theta_{H}\right)=b$ could be guaranteed at no cost. The cheapest contract that implements $e\left(\theta_{H}\right)=1$ would then set, by Proposition $1, w_{0}\left(\theta_{H}, b\right)=0$ and $w_{R}\left(\theta_{H}, b\right)=\frac{C_{b}}{\Delta}$ and the expected utility of a manager with a $\theta_{H}$ project who chooses $(f, e)=(b, 1)$ would then be $\left(\theta_{H}+\Delta\right) \frac{C_{b}}{\Delta}$. However, if (10) holds, such a utility would be lower than the private benefits obtainable with $(f, e)=(0, m)$. But then implementing $f\left(\theta_{H}\right)=b$ will indeed require some additional compensation.

${ }^{14}$ Covering the case in which (10) does not hold would require a slight generalization of Propositions 4 and 5 below. Qualitatively the solution to the optimal contract problem does not change, except that if $C_{m}$ is close to $\Delta R$ there may be cases in which the second best choice of $e$ becomes trivially zero for both types. In such cases, the dominance of $m b$ over $m m$ (Proposition 6) does not follow.

${ }^{15}$ The compensation schemes $w^{m b}$ and $w^{b b}$ are the unique minimum-cost schemes among the class of z-invariant schemes that implement $m b$ and $b b$, respectively. For each of these allocations, however, there is a continuum of alternative minimum-cost compensation schemes in which rewards vary with
} 
separation in $m b$ is attained by making rewards differ across financing choices. Second, when $f(\theta)=b$ the proposed schemes leave the manager an expected pecuniary reward of at least $C_{m}$, the value of the private benefits which he sacrifices by not choosing $e=0$. Third, the rewards that follow the choice of $f=m$ are always zero for two reasons: because otherwise the choice of market financing becomes unnecessarily more expensive to the shareholders and/or because by making market financing more attractive to managers the cost of inducing the choice of bank financing increases.

The scheme $w^{m b}$ implements a separating regime in which shareholders keep the $\theta_{L}$ project in market financing at a zero compensation cost and attract the $\theta_{H}$ project to bank financing at a cost of just $C_{m}$ :

Proposition 4 The compensation scheme $w^{m b}$ with

$$
w_{0}(z, b)=C_{m}-\left(\theta_{H}+\Delta\right) \frac{C_{b}}{\Delta}, w_{R}(z, b)=C_{m}+\left(1-\theta_{H}-\Delta\right) \frac{C_{b}}{\Delta}
$$

and $w_{0}(z, m)=w_{R}(z, m)=0$, for $z=\theta_{L}, \theta_{H}$, implements the market-bank allocation at the minimum cost.

The scheme $w^{b b}$ corresponds to a pooling regime in which the managers of both types of projects are attracted to bank financing, but those with a $\theta_{L}$ project receive expected rewards of just $C_{m}$ while those with a $\theta_{H}$ project receive $C_{m}+\left(\theta_{H}-\theta_{L}\right) \frac{C_{b}}{\Delta}$ :

Proposition 5 The compensation scheme $w^{b b}$ with

$$
w_{0}(z, b)=C_{m}-\left(\theta_{L}+\Delta\right) \frac{C_{b}}{\Delta}, \quad w_{R}(z, b)=C_{m}+\left(1-\theta_{L}-\Delta\right) \frac{C_{b}}{\Delta},
$$

and $w_{0}(z, m)=w_{R}(z, m)=0$, for $z=\theta_{L}, \theta_{H}$, implements the bank-bank allocation at the minimum cost.

z. For simplicity, but without loss of generality, the analysis below focuses on $w^{m b}$ and $w^{b b}$. 
The extra rent of $\left(\theta_{H}-\theta_{L}\right) \frac{C_{b}}{\Delta}$ received by the manager of the $\theta_{H}$ project is due to the need of inducing $(f, e)=(b, 1)$ in the $\theta_{L}$ project. Notice that inducing $f\left(\theta_{L}\right)=b$ requires, at least,

$$
\left(\theta_{L}+\Delta\right) w_{R}\left(\theta_{L}, b\right)+\left(1-\theta_{L}-\Delta\right) w_{0}\left(\theta_{L}, b\right) \geq C_{m}
$$

since the manager can obtain $C_{m}$ by choosing $(f, e)=(m, 0)$. Further, inducing $e\left(\theta_{L}\right)=1$ when $f\left(\theta_{L}\right)=b$ requires, by Proposition 1 , a bonus upon success such that

$$
w_{R}\left(\theta_{L}, b\right)-w_{0}\left(\theta_{L}, b\right) \geq \frac{C_{b}}{\Delta} .
$$

Now, suppose the manager of a $\theta_{H}$ project announces $\theta_{L}$ and chooses $(f, e)=(b, 1)$. Then, (11) and (12) imply that his expected payoff will amount at least $C_{m}+\left(\theta_{H}-\right.$

$\left.\theta_{L}\right) \frac{C_{b}}{\Delta}$ given the greater chances of success of his project and the presence of a positive bonus. The extra rent can be reduced to its minimum by making (11) and (12) hold with equality, as with $w^{b b}$.

We finish this section with the result that ranks $m m$ and $m b$ :

Proposition 6 The $m m$ allocation is dominated by the mb allocation.

The dominance of $m b$ over $m m$ can be immediately obtained after noting that $m m$ can be implemented at a zero compensation cost by setting $w_{x}(z, f)=0$ for all $x, z$, and $f$. Hence it generates an ex ante value of $\left[\mu \theta_{L}+(1-\mu) \theta_{H}\right] R$. Yet $w^{m b}$ implements $e=1$ with the $\theta_{H}$ project at a compensation cost of just $C_{m}$ so it generates an additional value for shareholders of $(1-\mu)\left(\Delta R-C_{m}\right)>0$.

\section{Equilibrium Regimes}

This section discusses the choice between the two potentially optimal financial regimes identified in the previous section: the market-bank regime (associated with the $m b$ 
allocation and the $w^{m b}$ scheme) and the bank-bank regime (associated with the $b b$ allocation and the $w^{b b}$ scheme).

\subsection{The market-bank regime}

In the $m b$ regime, the manager of a low profitability project resorts to market financing, is not subject to monitoring, receives a flat reward profile, and extracts private benefits at the cost of the project's probability of success. In contrast, the manager of a high profitability project resorts to bank financing, is monitored by the bank, receives incentive pay, and refrains from extracting private benefits at the cost of the project's probability of success. As a consequence, a low profitability project succeeds with probability $\theta_{L}$ whereas a high profitability project succeeds with probability $\theta_{H}+\Delta$. The cost of the manager's compensation is zero with $\theta_{L}$ and $C_{m}$ with $\theta_{H}$. The resulting ex ante value of the firm to shareholders is

$$
V_{0}^{m b}=\left[\mu \theta_{L}+(1-\mu) \theta_{H}\right] R+(1-\mu)\left(\Delta R-C_{m}\right)
$$

where the first term is the expected cash flow obtainable without managerial effort and the second is the expected cash flow (net of compensation costs) due to inducing $e\left(\theta_{H}\right)=1$.

\subsection{The bank-bank regime}

In the $b b$ regime, the manager resorts to bank financing irrespectively of his project's type, receives incentive pay, and refrains from extracting private benefits at the cost of the project's probability of success. As a result, low and high profitability projects succeed with probability $\theta_{L}+\Delta$ and $\theta_{H}+\Delta$, respectively. The cost of the manager's

compensation is $C_{m}$ with $\theta_{L}$ and $C_{m}+\left(\theta_{H}-\theta_{L}\right) \frac{C_{b}}{\Delta}$ with $\theta_{H}$. Hence the ex ante value 
of the firm to shareholders is

$$
V_{0}^{b b}=\left[\mu \theta_{L}+(1-\mu) \theta_{H}\right] R+\left[\Delta R-C_{m}-(1-\mu)\left(\theta_{H}-\theta_{L}\right) \frac{C_{b}}{\Delta}\right]
$$

which adds up the expected cash flow without managerial effort and the expected cash flow (net of compensation costs) due to now inducing $e\left(\theta_{L}\right)=e\left(\theta_{H}\right)=1$.

\subsection{Comparison of regimes}

A glance at the expressions for $V_{0}^{m b}$ and $V_{0}^{b b}$ makes it clear that the $b b$ regime produces a larger gross expected cash flow than the $m b$ regime, but at the cost of a higher compensation to the manager. Producing an extra $\Delta R$ under $\theta_{L}$ (i.e., with probability $\mu$ ) implies not only paying an extra $C_{m}$ to the manager in that case (which, absent other costs, would always be worthy) but also paying him an extra $\left(\theta_{H}-\theta_{L}\right) \frac{C_{b}}{\Delta}$ under $\theta_{H}$ (i.e., with probability $1-\mu$ ). Hence, the difference

$$
V_{0}^{b b}-V_{0}^{m b}=\mu\left(\Delta R-C_{m}\right)-(1-\mu)\left(\theta_{H}-\theta_{L}\right) \frac{C_{b}}{\Delta}
$$

may be positive or negative. In particular, it becomes negative when $\mu \rightarrow 0$ and positive when $\mu \rightarrow 1$; moreover, since $V_{0}^{b b}-V_{0}^{m b}$ is monotonically increasing in $\mu$, we obtain the following result:

Proposition 7 If the probability of holding a low profitability project, $\mu$, is below a critical level $\mu_{c} \in(0,1)$, the market-bank regime is optimal; otherwise, the bank-bank regime is optimal.

Intuitively, shareholders' choice between the $m b$ regime and the $b b$ regime is driven by the underlying private information problem. When shareholders opt for the separation of types, they lose on production efficiency if the project's profitability is low, but save on compensation costs if it is high. So the $m b$ regime is worthy insofar as 
the probability of holding a low profitability project is below a certain threshold $\mu_{c}$. Our next proposition summarizes the comparative statics of such a threshold.

Proposition 8 The critical level $\mu_{c}$ is: (i) decreasing in the incremental value of managerial effort, $\Delta$ and $R$; (ii) increasing in the severity of the moral hazard problem under market financing, $C_{m}$; (iii) increasing in the severity of the moral hazard problem under bank financing, $C_{b}$; and (iv) increasing in the severity of the private information problem, $\theta_{H}-\theta_{L}$.

The threshold $\mu_{c}$ is, on the one hand, reduced by factors that increase the direct surplus associated with using bank financing in the low profitability project. These include increases in the efficiency gains associated with the managerial effort, $\Delta$ and $R$, and decreases in the incremental private benefits obtainable under market financing, $C_{m}$ (which makes the manager less reluctant to submit himself to bank monitoring). On the other hand, $\mu_{c}$ is raised by factors that exacerbate the asymmetries of information and/or increase the extra rent received by the manager of a high profitability project in the $b b$ regime. These include increases in the private benefits obtainable under bank monitoring, $C_{b}$ (which increases the leverage required to provide incentives under bank financing), and increases in the difference in profitability across project types, $\theta_{H}-\theta_{L}$ (which increases the manager's gain due to such leverage). We postpone to Section 7 further discussion of the empirical implications of these results.

\subsection{On the possibility of renegotiation}

The financial regimes $m b$ and $b b$ emerge under the implicit assumption that their supporting compensation schemes $w^{m b}$ and $w^{b b}$, respectively, will not be renegotiated. However, optimal screening mechanisms frequently require some degree of com- 
mitment on the part of the principal. Without such a commitment, if the optimal mechanism produces some ex-post inefficiency, both parties can ex-post try to renegotiate the inefficiency away.

Here we examine the robustness of $m b$ and $b b$ to the possibility of renegotiating the manager's compensation scheme once the project's profitability type $\theta$ has been truthfully revealed. The analysis of regime $b b$ is straighforward. Under our assumptions, the choice of $(f, e)=(b, 1)$ is ex post efficient irrespectively of $\theta$, so we can conclude that $b b$ is renegotiation proof.

The analysis of the $m b$ regime is less straighforward. The rewards in $w^{m b}$ imply that if the project's profitability type is low, the manager chooses $f=m$. However, after observing this choice, shareholders might want to modify the manager's rewards so as to induce $e=1$. Two different possibilities arise. If the choice of $f$ is reversible, the rewards in $w^{b b}$ would suffice to induce the shift to $(f, e)=(b, 1)$ at the minimum cost to shareholders. However, if this renegotiation is anticipated, the high type will find this renegotiated rewards more desirable than his original ones in $w^{m b}$ so type separation will not be sustainable.

Alternatively, if the choice of $f$ is not reversible (say, because public securities have been issued and they are costly to retire from the market), shareholders can induce the choice of $e=1$ at a minimum cost by offering $w_{0}=0$ and $w_{R}=C_{m} / \Delta$ to the manager. However, it is possible that the cost of these new rewards outweigh the induced expected cash flow gains, in which case the renegotiation will not go through. ${ }^{16}$ If this were not the case, the manager with a high type project would again find the modified rewards more attractive than those in $w^{m b}$ so type separation would collapse.

\footnotetext{
${ }^{16}$ The new rewards cost, on average, $\left(\theta_{L}+\Delta\right) \frac{C_{m}}{\Delta}$ under a low type project, while the induced expected cash flow gain is $\Delta R$. Our assumptions do not imply any ordering between these two quantities.
} 
In conclusion, sustaining $m b$ may require the commitment from shareholders not to renegotiate the manager's compensation package. Absent such a commitment, type separation will be harder, in general, to obtain.

\section{The Valuation Effects of the Financing Decision}

Private information influences the main results of the model. When the managerial contract is designed, shareholders know that the manager's financing decision $f$ will be based on his observation of project type $\theta$. The regimes $m b$ and $b b$ differ fundamentally in the information revealed to shareholders through $f$. In $b b$ the financing decision is identical for the two types, hence it does not reveal any information. In contrast, in $m b$ the financing decision varies with project type, so the market value of the firm may change at the announcement of $f$. Therefore a necessary and sufficient condition to observe valuation effects in equilibrium is the prevalence of the $m b$ regime. ${ }^{17}$

Suppose the $m b$ regime is indeed optimal. Then, when the manager chooses market financing, shareholders learn that the project is of type $\theta_{L}$ whose optimal contract induces $e\left(\theta_{L}\right)=0$ and specifies zero rewards to the manager. Hence, their valuation of the firm shifts to:

$$
V_{m}^{m b}=\theta_{L} R
$$

where the subscript $m$ identifies the observed financing choice. Alternatively, if the manager chooses bank financing, shareholders learn that the project is of type $\theta_{H}$ whose optimal contract induces $e\left(\theta_{L}\right)=1$ and specifies rewards to the manager with an expected value of $C_{m}$. Hence, their valuation of the firm shifts to:

$$
V_{b}^{m b}=\left(\theta_{H}+\Delta\right) R-C_{m}
$$

Note that $V_{b}^{m b}$ is larger than $V_{m}^{m b}$ for two reasons. First because of the difference

\footnotetext{
${ }^{17}$ The conditions under which this regime prevails have been described in Proposition 7 .
} 
in the project's intrinsic profitability types, $\theta_{H}>\theta_{L}$, and second because of the net value coming from inducing managerial effort, $\Delta R-C_{m}>0$.

This last element, in turn, reflects the contribution of bank financing to the value of the firm. Given $f$, providing the incentives for $e=1$ in a $\theta_{H}$ project implies an expected reward of at least $\left(\theta_{H}+\Delta\right) \frac{C_{f}}{\Delta}>C_{f}$, a quantity that increases with $C_{f}$. By reducing $C_{f}$, bank monitoring reduces the cost of managerial compensation from $\left(\theta_{H}+\Delta\right) \frac{C_{m}}{\Delta}$ to $\max \left\{C_{m},\left(\theta_{H}+\Delta\right) \frac{C_{b}}{\Delta}\right\}=C_{m} \cdot{ }^{18}$ This identifies the channel through which banks contribute to firm value in this model. In addition, banks are endogenously associated with good projects. Therefore,

Proposition 9 In the market-bank regime, the announcement of the manager's decision to use bank (market) financing produces a positive (negative) variation in the firm's market value.

The positive and negative valuation effects referred in Proposition 9 can be quantified using (13), (16), and (17) as follows:

$$
\begin{gathered}
V_{b}^{m b}-V_{0}^{m b}=\mu\left[\left(\theta_{H}-\theta_{L}\right) R+\left(\Delta R-C_{m}\right)\right], \\
V_{0}^{m b}-V_{m}^{m b}=(1-\mu)\left[\left(\theta_{H}-\theta_{L}\right) R+\left(\Delta R-C_{m}\right)\right] .
\end{gathered}
$$

The size of the positive (negative) reaction to bank (market) financing is directly proportional to the difference between the net expected cash flow generated by high and low profitability types, $V_{b}^{m b}-V_{m}^{m b}$, and to the ex ante probability that the project is of the low (high) profitability type. ${ }^{19}$ So the positive market response to bank loans

\footnotetext{
${ }^{18}$ Recall assumption (10).

${ }^{19}$ While the positive reaction to bank financing seems consistent with abnormal returns observed at the announcement of bank loans, the negative reaction to market financing has a less obvious empirical counterpart. It is clearly consistent with the well-documented negative response to public equity issuance as well as with Datta, Iskandar-Datta, and Patel (2000), who document a negative response to initial public debt offerings.
} 
becomes quantitatively more significant as $\mu \leq \mu_{c}$ approaches $\mu_{c}$ (critical value above which $b b$ replaces $m b)$. Changes in $\Delta, R$, and the difference $\theta_{H}-\theta_{L}$ relate positively with the size of the response, while $C_{m}$ affects it negatively. We discuss further the empirical implications of these results in Section 7.

\section{Another Role for Market-based Compensation}

So far we have assumed that contracts contingent upon the mode of financing chosen by the manager are enforceable. However, in practice, it is unusual to observe managerial contracts with rewards directly dependent on the manager's financing choices. In this section we show that the direct contractibility on $f$ is not necessary for the implementation of the compensation schemes associated with the optimal financial regimes. The market reaction associated with the announcement of $f$ can be used to implement the optimal contracts by means of market-based compensation.

Consider first the $m b$ regime. The compensation scheme $w^{m b}$ can be implemented by granting the manager the following compensation package consisting of stock appreciation rights:

- If at $t=2$ the firm's stock price appreciates up to $V_{b}^{m b}=\left(\theta_{H}+\Delta\right) R-C_{m}$ the manager receives

(a) a reward in cash of $C_{m}-\left(\theta_{H}+\Delta\right) \frac{C_{b}}{\Delta}>0$,

(b) a reward in non-transferable shares entitling him to a fraction $s=\frac{C_{b}}{\Delta R}<1$ of the cash flow of the firm at $t=3$.

- In the absence of the required stock price appreciation, the manager receives no reward. 
To see how this package works, consider the market reaction to the manager's financing decision is as discussed in Section 5 and the possible scenarios faced by a manager who has discovered that the firm's type is $\hat{\theta}$. If he chooses $f=m$, the firm's stock price will go from $V_{0}^{m b}$ down to $V_{m}^{m b}$ and the manager will be paid zero irrespectively of the success or failure of the project. Consequently he will choose $e=0$ and obtain an expected utility of $C_{m}$ coming from private benefits.

Alternatively, if he chooses $f=b$, the firm's stock price will go from $V_{0}^{m b}$ up to $V_{b}^{m b}$ and he will receive a safe cash payment of $C_{m}-\left(\theta_{H}+\Delta\right) \frac{C_{b}}{\Delta}$ and the possibility of an additional cash payment of $s R=\frac{C_{b}}{\Delta}$ if the project succeeds. Thus, choosing $e=0$, his expected utility will be:

$$
\left[C_{m}-\left(\theta_{H}+\Delta\right) \frac{C_{b}}{\Delta}\right]+\hat{\theta} s R+C_{b}=C_{m}-\left(\theta_{H}-\hat{\theta}\right) \frac{C_{b}}{\Delta}
$$

while, choosing $e=1$, it will be:

$$
\left[C_{m}-\left(\theta_{H}+\Delta\right) \frac{C_{b}}{\Delta}\right]+(\hat{\theta}+\Delta) s R+C_{b}=C_{m}-\left(\theta_{H}-\hat{\theta}\right) \frac{C_{b}}{\Delta},
$$

which happens to be identical to the previous one. Hence if $\hat{\theta}=\theta_{L}$ the manager strictly prefers $(f, e)=(m, 0)$ to any other alternative, whereas if $\hat{\theta}=\theta_{H}$ he is indifferent between the choices $(m, 0),(b, 0)$ and $(b, 1)$, which are preferred to $(m, 1) .{ }^{20}$ So the intended allocation is implemented with the described compensation package.

It is immediate to check that the above compensation package has an expected cost identical to the compensation scheme referred in Proposition 4. As a result:

Proposition 10 The market-bank regime can be implemented by a compensation package based exclusively on stock market performance.

Consider next the implementation of the $b b$ regime. In this case the compensation package will establish that:

\footnotetext{
${ }^{20}$ To break this indifference in favor of $(b, 1)$ one can simply increase a little bit the award of shares associated with the required stock price appreciation.
} 
- If at $t=2$ the firm's stock does not depreciate the manager receives

(a) a reward in cash of $C_{m}-\left(\theta_{L}+\Delta\right) \frac{C_{b}}{\Delta}>0$,

(b) a reward in non-transferable shares entitling him to a fraction $s=\frac{C_{b}}{\Delta R}<1$ of the cash flow of the firm at $t=3$.

- If the stock price falls the manager receives no reward.

The main difference with respect to the $m b$ regime is that now using market financing is an out-of-the-equilibrium choice for the manager. In the proof of Proposition 11, we discuss how this affects matters slightly from a formal point of view. However, the substance of the result does not change: the proposed package has an expected cost identical to the compensation scheme referred in Proposition 5. So,

Proposition 11 The bank-bank regime can be implemented by a compensation package based exclusively on stock market performance.

Summing up, Propositions 10 and 11 contain decentralization results which imply that if the complexity of the financing decisions corresponding to our variable $f$ impedes contracting directly on them, contracting on market performance may be a good substitute. In particular, the stock market reaction to bank financing may become the means for providing incentives to the manager and, consequently, attaining the gains in value that the reaction reflects.

\section{Discussion of the Results}

We organize the discussion of our results in two parts. First, we comment on the implications of private information and the effectiveness of bank monitoring for the choice of bank financing and its announcement effects, comparing our model with its 
main theoretical alternative -a model in which banks play a pure certification role. Second, we comment on the linkages between managerial compensation and financing decisions (and, more generally, between governance and managerial submission to monitoring) that our theory unveils.

\subsection{Private information and the role of banks}

In our model the problem of inducing managers to submit to bank monitoring is fundamentally affected by private information: it makes it costly to attract the managers of low profitability firms to the bank. This private information cost may drive shareholders into the separating $m b$ regime, where low profitability firms are kept away from bank financing and the announcement effects of bank loans follow.

The outcome in $m b$ resembles that of a model in which banks play a certification role: high profitability firms are willing to incur the bank certification cost, while low profitability firms are not. In such a model, as in ours, bank loan announcements would be followed by positive stock market reactions. However, other implications differ substantially across this model and ours. For instance, in a pure certification setting a less severe informational asymmetry (i.e., a lower spread of profitability types, $\left.\theta_{H}-\theta_{L}\right)$ would reduce the use of bank financing. In our model, in contrast, having a lower type spread reduces the cost of attracting the managers to banks so it makes bank financing more widespread.

A recent paper by Krishnaswami, Spindt, and Subramaniam (1999) that examines the relative use of private and public financing in US corporations offers evidence consistent with our model. In fact, they find no evidence that a higher degree of informational asymmetry (measured either by the standard deviation of the market model residuals or by firm age) is associated with a greater use of private financing. Moreover, they find that, when the private information problem is severe, firms with 
positive private information about their future (identified as those experiencing positive abnormal earnings after their financing) are more inclined to use bank financing. Notice that their first finding goes against the main prediction of the pure screening model, but it would certainly be consistent with our model if some firms in their sample operate in the $b b$ regime and others in the $m b$ regime. ${ }^{21}$ Their second finding suggests a logic consistent with our $m b$ regime: only when the private information problem is severe enough the use of bank financing becomes a signal of good future performance.

Another difference between the implications of a pure certification model and of our analysis emerges by examining the effects of the degree of asymmetric information on the average stock price response to bank loans. In our model, larger informational asymmetries make shareholders less prone to induce the low profitability firms to use bank monitoring, thereby making the use of bank loans a stronger signal of high profitability. In the pure certification model, a composition effect would work in exactly the opposite direction: larger informational asymmetries would make firms of intermediate profitability willing to incur the certification cost, and hence could make, on average, the use of bank financing a weaker signal of high profitability. Consistent with our results, the evidence shows a positive relationship between the degree of asymmetric information and the size of the announcement effects. For instance, Best and Zhang (1993) show that firms with a greater dispersion in analysts' earning forecasts tend to experience larger stock price run-ups at the announcement of a new bank loan. Likewise, Billet, Flannery, and Garfinkel (1995) find that the reaction to new bank loans is positively correlated with the idiosyncratic component of borrowers' stock returns.

\footnotetext{
${ }^{21}$ This is because the degree of asymmetric information is positively correlated with the incidence of $m b$ and thereby with a less frequent use of private financing.
} 
Improvements in bank effectiveness will also have different implications in our model than they would in a pure certification model. In the latter, more effective banks would provide a better selection of bank borrowers and their loans should thus be associated with larger positive stock market reactions. In our model, if banks are more effective in ameliorating the moral hazard problem (so that in their presence managers' potential private benefits $C_{b}$ are lower), the average stock market reaction to bank loans is smaller. In fact firms, irrespectively of their profitability type, would opt for bank financing and, consequently, no market reaction to bank loans should be observed. Hence we should expect a larger reaction to bank financing among firms for which banks are comparatively less effective monitors. ${ }^{22}$

\subsection{Governance and managerial submission to monitoring}

The implementation of $m b$ and $b b$ using stock based managerial compensation allows us to offer novel predictions relative to the correlation between financing choices and managerial compensation. Particularly, our results imply a positive cross-sectional correlation between the responsiveness of the market to financing choices (present in $m b$ but not in $b b$ ) and the sensitivity of managerial pay to performance (larger in $m b$ than in $b b$ ). In addition, pay-performance sensitivity should be larger among firms that rely more on bank financing. These predictions, however, emerge from the contract that maximizes ex ante shareholder value so they would apply to firms whose governance system works reasonably well. With poor governance, we should expect less submission to bank monitoring and lower pay-performance sensitivities.

As far as we know, no empirical study has related bank monitoring with man-

\footnotetext{
${ }^{22}$ This prediction is consistent with Bayless and Chaplinsky (1991), who find that firms which are ex ante less likely to use bank loans are those receiving a more positive reaction at the announcement, and with Hadlock and James (2000), who find that the reaction is only significant among firms with public debt outstanding, that is, those for which banks revealed less attractive in the past.
} 
agerial compensation and governance. However, if we accept leverage as a proxy for the intensity of monitoring, the evidence in Berger, Ofek, and Yermack (1997) seems consistent with the predictions of our model. These authors examine the relationship between leverage and some proxies of managerial entrenchment (presumably related to the quality of governance). They report that leverage (in our interpretation, the degree of managers' "submission to monitoring") is positively correlated with payperformance sensitivity, is lower when CEOs are entrenched, and increases in the aftermath of entrenchment-reducing shocks. ${ }^{23}$

Despite we emphasize the relationship between governance, compensation, and the managerial submission to monitoring present in the choice of bank loans, the logic of our analysis may extend to other managerial decisions with a similar impact on the subsequent incentive problem. These include any managerial proposal of changes in financing, governance, accounting, auditing or internal organization that reduce the private benefits that managers could obtain by deviating from value maximization. A prominent example of such type of proposals are leveraged buyouts (LBOs) which, in line with our predictions, frequently entail the introduction of both greater discipline through debt and explicit incentive pay for the managers. Our analysis suggests that LBOs would tend to follow the reception by managers of favorable information about their firms and would support the wisdom that part of the LBO cash flow improvement is due to enhanced incentives but another part is the result of reverse causation. ${ }^{24}$

\footnotetext{
${ }^{23}$ From a monitoring viewpoint, what probably matters is not the payoff structure of the security issued (i.e., debt versus equity) but whether it is held privately or publicly. In this respect, Wruck (1989) shows that, in contrast with the negative market reaction to public equity placements, private equity placements associate with a positive market reaction.

${ }^{24}$ See Grinblatt and Titman (1998), pp. 685-687.
} 


\section{Concluding Remarks}

We have examined the determinants of the use of bank financing in a novel setting. In our model there is a separation between ownership and control. Managers enjoy full discretion on both investment and financing decisions so inducing managers to submit themselves to the discipline of bank financing requires a proper incentive contract.

The design of the incentive contract that shareholders would wish to offer to managers is fundamentally affected by the existence of private information concerning firms' profitability. To induce managers of both high and low profitability firms to choose bank financing requires the managers of the high profitability firms to capture additional informational rents. These rents can be reduced by offering separating contracts that induce high profitability firms to choose bank financing and low profitability firms to choose market financing. We have shown that when the asymmetries of information are substantial, separating contracts are optimal. We have also provided an intuitive implementation of the optimal separating contract through market-based compensation.

The optimal separating contract presents one of the paper's main findings: an association between firm profitability, high powered managerial incentives, and bank financing. While the association between managerial incentives and bank financing is a central theme in the literature on bank monitoring, the association between them and firm profitability relates entirely to the private information effect identified here. The triple-sided association is consistent with the event study evidence on the positive stock market reaction to bank loan announcements and leads to novel empirical predictions about the linkage between financing choices and managerial compensation. 


\section{APPENDIX}

Proof of Proposition 1. Under a given financing mode $f(\theta)$, inducing $e(\theta)=1$ requires the manager's utility with $e=1$,

$$
(1-\theta-\Delta) w_{0}(\theta, f(\theta))+(\theta+\Delta) w_{R}(\theta, f(\theta))
$$

to be at least as large as with $e=0$,

$$
(1-\theta) w_{0}(\theta, f(\theta))+\theta w_{R}(\theta, f(\theta))+C(f(\theta))
$$

Such a condition is equivalent to (9)

Proof of Proposition 2. This proof has two parts. Both are done by contradiction.

We start with a proposed allocation which is implemented at a minimum cost by some contract $w^{0}$ with components $w_{x}^{0}(z, f)$, where $x=0, R, z=\theta_{L}, \theta_{H}$, and $f=m, b$. Then we show that it is possible to find some alternative contract, always called $w^{\prime}$ to save on notation, that leads to a different allocation and provides greater ex ante shareholder value.

Part 1: Suboptimality of $(\mathbf{b}, \mathbf{0})$. Consider an allocation with $\left(f\left(\theta_{j}\right), e\left(\theta_{j}\right)\right)=(b, 0)$ for some $j=L, H$ which is implemented at a minimum cost by $w^{0}$. Denote by $i$ the type different from $j$. Then:

1. If $e\left(\theta_{i}\right)=0$, consider the contract $w^{\prime}$ with components $w_{x}^{\prime}(z, f)=0$ for all $x, z$, and $f$. This contract implements $(f, e)=(m, 0)$ for both types, so it generates the same gross value as the original contract. Moreover, it has a zero compensation cost, while inducing $f\left(\theta_{j}\right)=b$ with $w^{0}$ implies

$$
\theta_{j} w_{R}^{0}\left(\theta_{j}, b\right)+\left(1-\theta_{j}\right) w_{0}^{0}\left(\theta_{j}, b\right) \geq C_{m}-C_{b}>0
$$


where the first inequality follows from the revealed preference for $(b, 0)$ when $(m, 0)$ was available. Hence $w^{\prime}$ saves on compensation for, at least, type $j$.

2. If $e\left(\theta_{i}\right)=1$, there are two subcases:

(a) If $f\left(\theta_{i}\right)=m$, consider the contract $w^{\prime}$ with components $w_{0}^{\prime}(z, m)=w_{x}^{\prime}(z, b)$ $=0$ for all $x$ and $z$, and $w_{R}^{\prime}(z, m)=\frac{C_{m}}{\Delta}$ for all $z$. By Proposition 1 , this contract implements $(f, e)=(m, 1)$ for both types at a minimum cost. It does not change the effort decision and minimizes the compensation cost for type $i$, while it creates additional shareholder value for type $j$. In particular, for type $j$ it produces extra gross value $\Delta R$ at a compensation cost of $\left(\theta_{j}+\Delta\right) \frac{C_{m}}{\Delta}$. Instead, $w^{0}$ implies a compensation cost of, at least, $\left(\theta_{j}+\Delta\right) \frac{C_{m}}{\Delta}-C_{b}$ since the manager could obtain, at least, $\left(\theta_{j}+\Delta\right) \frac{C_{m}}{\Delta}$ by announcing $\theta_{i}$ and choosing $(f, e)=(m, 1)$, and $C_{b}$ is the maximum non-pecuniary income obtainable with $(f, e)=(b, 0)$. So shareholder value increases by, at least, $\Delta R-C_{b}>0$.

(b) If $f\left(\theta_{i}\right)=b$, consider the contract $w^{\prime}$ with components $w_{x}^{\prime}(z, m)=0$ for all $x$ and $z$, and $w_{x}^{\prime}(z, b)=w_{x}^{0}\left(\theta_{i}, b\right)$ for all $x$ and $z$. This contract does not change the decisions or the compensation cost for $i$. For type $j$, it implements either $(f, e)=(b, 1)$ or $(f, e)=(m, 0)$. In the first case, gross value increases by $\Delta R$ while the compensation cost is $\left(\theta_{j}+\Delta\right) w_{R}^{0}\left(\theta_{i}, b\right)+$ $\left(1-\theta_{j}-\Delta\right) w_{0}^{0}\left(\theta_{i}, b\right)$. Under $w^{0}$, however, the compensation cost amounts at least $\left(\theta_{j}+\Delta\right) w_{R}^{0}\left(\theta_{i}, b\right)+\left(1-\theta_{j}-\Delta\right) w_{0}^{0}\left(\theta_{i}, b\right)-C_{b}$, since the manager could announce $\theta_{i}$ and choose $(f, e)=(m, 1)$, and $C_{b}$ is the maximum non-pecuniary income obtainable with $(f, e)=(b, 0)$. So $w^{\prime}$ increases shareholder value by, at least, $\Delta R-C_{b}>0$. In the second case, gross value does not increase but the compensation cost is zero, so the saving in compensa- 
tion amounts $\theta_{j} w_{R}^{0}\left(\theta_{j}, b\right)+\left(1-\theta_{j}\right) w_{0}^{0}\left(\theta_{j}, b\right) \geq C_{m}-C_{b}>0$, where the first inequality follows from the revealed preference for $(b, 0)$ under $w^{0}$, when $(m, 0)$ was available.

Part 2: Suboptimality of $(\mathbf{m}, \mathbf{1})$. Consider an allocation with $\left(f\left(\theta_{j}\right), e\left(\theta_{j}\right)\right)=$ $(m, 1)$ for some $j=L, H$ which is implemented at a minimum cost by $w^{0}$. Consider also the alternative contract $w^{\prime}$ with components $w_{x}^{\prime}(z, m)=0$ for all $x$ and $z$, $w_{0}^{\prime}(z, b)=w_{0}^{0}\left(\theta_{j}, m\right)$ for all $z$, and $w_{R}^{\prime}(z, b)=w_{R}^{0}\left(\theta_{j}, m\right)-\varepsilon$ for all $z$, where $\varepsilon$ is a small positive number. Denote by $i$ the type different from $j$.

Notice first that, by Proposition 1,

$$
\lim _{\varepsilon \rightarrow 0}\left[w_{R}^{\prime}(z, b)-w_{0}^{\prime}(z, b)\right]=w_{R}^{0}(z, m)-w_{0}^{0}(z, m) \geq \frac{C_{m}}{\Delta}>\frac{C_{b}}{\Delta}
$$

so, for any $k=i, j$,

$$
\lim _{\varepsilon \rightarrow 0}\left[\left(\theta_{k}+\Delta\right) w_{R}^{\prime}(z, b)-\left(1-\theta_{k}-\Delta\right) w_{0}^{\prime}(z, b)\right] \geq\left(\theta_{k}+\Delta\right) \frac{C_{m}}{\Delta}>C_{m}
$$

Thus, for sufficiently small $\varepsilon, w^{\prime}$ implements $\left(f\left(\theta_{j}\right), e\left(\theta_{j}\right)\right)=\left(f\left(\theta_{i}\right), e\left(\theta_{i}\right)\right)=(b, 1)$. Moreover, relative to $w^{0}$, this contract saves an amount $\left(\theta_{k}+\Delta\right) \varepsilon$ on compensation for type $j$. For type $i$ there are two cases to consider.

1. If $e\left(\theta_{i}\right)=0$, gross value increases by $\Delta R$ while the compensation cost is $\left(\theta_{i}+\right.$ $\Delta)\left[w_{R}^{0}\left(\theta_{j}, m\right)-\varepsilon\right]+\left(1-\theta_{i}-\Delta\right) w_{0}^{0}\left(\theta_{j}, m\right)$. Under $w^{0}$, however, the compensation cost amounts, at least, $\left(\theta_{i}+\Delta\right) w_{R}^{0}\left(\theta_{j}, m\right)+\left(1-\theta_{i}-\Delta\right) w_{0}^{0}\left(\theta_{j}, m\right)-C_{m}$, since the manager could announce $\theta_{j}$ and choose $(f, e)=(m, 1)$, and $C_{m}$ is the maximum non-pecuniary income obtainable with $e=0$. But then $w^{\prime}$ increases shareholder value by, at least, $\Delta R+\left(\theta_{i}+\Delta\right) \varepsilon-C_{m}>0$.

2. If $e\left(\theta_{i}\right)=1$, gross value does not change, but the compensation cost is $\left(\theta_{i}+\right.$ $\Delta)\left[w_{R}^{0}\left(\theta_{j}, m\right)-\varepsilon\right]+\left(1-\theta_{i}-\Delta\right) w_{0}^{0}\left(\theta_{j}, m\right)$. Under $w^{0}$, however, the compensation 
cost amounts, at least, $\left(\theta_{i}+\Delta\right) w_{R}^{0}\left(\theta_{j}, m\right)+\left(1-\theta_{i}-\Delta\right) w_{0}^{0}\left(\theta_{j}, m\right)$, since the manager could announce $\theta_{j}$ and choose $(f, e)=(m, 1)$, and his non-pecuniary income is zero when $e=1$. But then shifting to $w^{\prime}$ increases shareholder value by, at least, $\left(\theta_{i}+\Delta\right) \varepsilon>0$.

Proof of Proposition 3. We follow the same logic as in the previous proof. Consider an allocation with $e\left(\theta_{L}\right)=1$ and $e\left(\theta_{H}\right)=0$ which is implemented at a minimum cost by the contract $w^{0}$. Let $f_{L}=f\left(\theta_{L}\right)$, then Proposition 1 implies that

$$
w_{R}^{0}\left(\theta_{L}, f_{L}\right)-w_{0}^{0}\left(\theta_{L}, f_{L}\right) \geq \frac{C_{f_{L}}}{\Delta}
$$

whereas

$$
w_{R}^{0}\left(\theta_{H}, f\left(\theta_{H}\right)\right)-w_{0}^{0}\left(\theta_{H}, f\left(\theta_{H}\right)\right)<\frac{C_{f\left(\theta_{H}\right)}}{\Delta} .
$$

Consider an alternative contract $w^{\prime}$ with components $w_{x}^{\prime}\left(z, f_{L}\right)=w_{x}^{0}\left(\theta_{L}, f_{L}\right)$ for all $x$ and $z$, and $w_{x}^{\prime}(z, f)=0$ for all $x, z$, and $f \neq f_{L}$. Clearly this contract implements $(f, e)=\left(f_{L}, 1\right)$ for type $L$, but also for type $H$. To see this, notice that, by Proposition 1, (20) suffices for $e=1$ if $f\left(\theta_{H}\right)=f_{L}$, but this is the case since, given (20), the payoff associated with $f=f_{L}$ is increasing in $\theta$, while that associated with $f \neq f_{L}$ is flat. Therefore, for type $H, w^{\prime}$ increases gross value by $\Delta R$ and has a compensation cost of $Q \equiv\left(\theta_{H}+\Delta\right) w_{R}^{0}\left(\theta_{L}, f_{L}\right)+\left(1-\theta_{H}-\Delta\right) w_{0}^{0}\left(\theta_{L}, f_{L}\right)$. Notice, however, that $w^{0}$ entails a compensation cost of, at least, $Q-C_{m}$ for type $H$, since $Q$ is the utility that the manager could obtain announcing $\theta_{L}$ and choosing $(f, e)=(b, 1)$ and $C_{m}$ is the maximum non-pecuniary income that he can possibly obtain. But then shifting to $w^{\prime}$ increases shareholder value by, at least, $\Delta R-C_{m}>0$.

Proof of Proposition 4. This proof involves two parts. First we prove that $w^{m b}$ implements the $m b$ allocation. Then we show that it does so at the minimum cost. 
Part 1: Implementation. $w^{m b}$ must satisfy the incentive compatibility conditions

$$
\begin{gathered}
U\left(a\left(\theta_{L}\right), w^{m b} ; \theta_{L}\right) \geq U\left(a, w^{m b} ; \theta_{L}\right) \text { for all } a \\
U\left(a\left(\theta_{H}\right), w^{m b} ; \theta_{H}\right) \geq U\left(a, w^{m b} ; \theta_{H}\right) \text { for all } a,
\end{gathered}
$$

where $a\left(\theta_{L}\right)=\left(\theta_{L}, m, 0\right)$ and $a\left(\theta_{H}\right)=\left(\theta_{H}, b, 1\right)$. Checking that $w^{m b}$ satisfies these conditions is immediate. Notice that the payments in $w^{m b}$ are invariant to $z$, so the manager does not hesitate about truthfully revealing his project type by choosing $z(\theta)=\theta$ for $\theta=\theta_{L}, \theta_{H}$. In addition, by Proposition 1 , the differences $w_{R}(z, f)-$ $w_{0}(z, f)$ for $z=\theta_{L}, \theta_{H}$ and $f=m, b$ are sufficient for implementing $e(\theta)=0$ insofar as $f(\theta)=m$, and $e(\theta)=1$ insofar as $f(\theta)=b$. But then, the choice of action $\left(\theta_{L}, m, 0\right)$ under $\theta_{L}$ is guaranteed, since it leads the manager to obtain a utility greater than under the best bank-financing alternatives, $\left(\theta_{L}, b, 1\right)$ and $\left(\theta_{H}, b, 1\right)$ :

$$
C_{m}>\left(1-\theta_{L}-\Delta\right) w_{0}(z, b)+\left(\theta_{L}+\Delta\right) w_{R}(z, b), \quad \text { for } z=\theta_{L}, \theta_{H}
$$

Similarly, the choice of action $\left(\theta_{H}, b, 1\right)$ under $\theta_{H}$ is guaranteed by the fact that the manager's utility under such choice is as high as under the best market-financing alternatives, $\left(\theta_{L}, m, 0\right)$ and $\left(\theta_{H}, m, 0\right)$ :

$$
\left(1-\theta_{H}-\Delta\right) w_{0}\left(\theta_{H}, b\right)+\left(\theta_{H}+\Delta\right) w_{R}\left(\theta_{H}, b\right)=C_{m}
$$

Hence, $w^{m b}$ definitely implements $m b$.

Part 2: Minimum cost. Notice first that under $\theta_{L}$ the proposed scheme involves no equilibrium payment to the manager, thereby leaving no room for improvement on this dimension. Notice next that under $\theta_{H}$ there is no room for improvement either, since the expected payment to the manager is just $C_{m}$, the minimum pecuniary compensation compatible with the absence of non-pecuniary income under $e\left(\theta_{H}\right)=1$ and the possibility of obtaining $C_{m}$ by setting $(f, e)=(m, 0)$. 
Proof of Proposition 5. As in the previous proposition we first prove that $w^{b b}$ implements the $b b$ allocation. Then we show that it does so at the minimum cost.

Part 1: Implementation. $w^{b b}$ must satisfy the incentive compatibility conditions

$$
\begin{gathered}
U\left(a\left(\theta_{L}\right), w^{b b} ; \theta_{L}\right) \geq U\left(a, w^{b b} ; \theta_{L}\right) \quad \text { for all } a \\
U\left(a\left(\theta_{H}\right), w^{b b} ; \theta_{H}\right) \geq U\left(a, w^{b b} ; \theta_{H}\right) \quad \text { for all } a
\end{gathered}
$$

where $a(\theta)=(\theta, b, 1)$ for $\theta=\theta_{L}, \theta_{H}$. Checking that $w^{b b}$ satisfies these conditions is immediate. Again, the payments in $w^{b b}$ are invariant to $z$, so the manager does not hesitate about truthfully revealing his project type by choosing $z(\theta)=\theta$ for $\theta=\theta_{L}, \theta_{H}$. In addition, the differences $w_{R}(z, f)-w_{0}(z, f)$ for $z=\theta_{L}, \theta_{H}$ and $f=m, b$ are sufficient by Proposition 1 for implementing $e(\theta)=0$ insofar as $f(\theta)=m$, and $e(\theta)=1$ insofar as $f(\theta)=b$. But then, the manager's utility following his intended action $\left(\theta_{L}, b, 1\right)$ under $\theta_{L}$ is as high as under the best market-financing alternatives, $\left(\theta_{L}, m, 0\right)$ and $\left(\theta_{H}, m, 0\right)$ :

$$
\left(1-\theta_{L}-\Delta\right) w_{0}(z, b)+\left(\theta_{L}+\Delta\right) w_{R}(z, b)=C_{m}
$$

so his intended action can be implemented. Similarly, the choice of $\left(\theta_{H}, b, 1\right)$ under $\theta_{H}$ is guaranteed by the fact that the manager's utility under such choice is greater than under the best market-financing alternatives, $\left(\theta_{L}, m, 0\right)$ and $\left(\theta_{H}, m, 0\right)$ :

$$
\left(1-\theta_{H}-\Delta\right) w_{0}\left(\theta_{H}, b\right)+\left(\theta_{H}+\Delta\right) w_{R}\left(\theta_{H}, b\right)=C_{m}+\left(\theta_{H}-\theta_{L}\right) \frac{C_{b}}{\Delta}>C_{m} .
$$

Thus, $w^{b b}$ definitely implements $b b$.

Part 2: Minimum cost. Notice first that under $\theta_{L}$, the proposed scheme involves an equilibrium payment to the manager of just $C_{m}$ : the minimum amount that, given the absence of private benefits with $e\left(\theta_{L}\right)=1$, is compatible with the possibility of obtaining $C_{m}$ by just setting $(f, e)=(m, 0)$. So there is no room for improvement 
on this dimension. Note next that, $e\left(\theta_{L}\right)=1$ requires, by Proposition $1, w_{R}\left(\theta_{L}, b\right)-$ $w_{0}\left(\theta_{L}, b\right) \geq \frac{C_{b}}{\Delta}$. Now, suppose that the project has profitability $\theta_{H}$ but the manager mimics the action intended for $\theta_{L}$. Then his utility will exceed in $\left(\theta_{H}-\theta_{L}\right) \frac{C_{b}}{\Delta}$ that attainable under $\theta_{L}$. Hence, the equilibrium utility for the manager under $\theta_{H}$ cannot be lower than $C_{m}+\left(\theta_{H}-\theta_{L}\right) \frac{C_{b}}{\Delta}$. But then, the absence of private benefits when $e\left(\theta_{H}\right)=1$ implies that the expected payment to the manager under $\theta_{H}$ cannot be lower than $C_{m}+\left(\theta_{H}-\theta_{L}\right) \frac{C_{b}}{\Delta}$. This is precisely the cost of $w^{b b}$ under $\theta_{H}$, so there is no room for improvement on this dimension either.

Proof of Propositions 6-10. These propositions are proved by the arguments that appear in the text.

Proof of Proposition 11. In the $b b$ regime using market (rather than bank) financing is an out-of-equilibrium managerial action. Yet, the possibility of the manager deviating in such a way raises the issue of what the beliefs determining the market value of the firm in such a case would be. We will simply assume that investors believe that the manager is equally likely to deviate under the two possible values of $\theta$. After the deviation, and because the compensation scheme is either flat (if the value of the firm falls) or not levered enough to provide incentives under market financing (if it remains at $V_{0}^{b b}$ ), the optimal effort would be $e=0$, irrespectively of $\theta$. Accordingly, after the deviation, the market value of the company would fall from $V_{0}^{b b}$ (see equation (14)) to $\left[\mu \theta_{L}+(1-\mu) \theta_{H}\right] R<V_{0}^{b b}$. But this is enough for the manager not to have incentives to deviate under the proposed market-based compensation package. 


\section{References}

[1] Aghion, Philippe, and Jean Tirole, 1997, "Formal and Real Authority in Organizations," Journal of Political Economy 105, 1-29.

[2] Bayless, Mark, and Susan Chaplinsky, 1991, "Expectations of Security Type and the Information Content of Debt and Equity Offers," Journal of Financial Intermediation 1, 195-214.

[3] Berger, Philip, Eli Ofek, and David L. Yermack, 1997, "Managerial Entrenchment and Capital Structure Decisions," Journal of Finance 52, 1411-1438.

[4] Best, Ronald, and Hang Zhang, 1993, "Alternative Information Sources and the Information Content of Bank Loans," Journal of Finance 48, 1507-1522.

[5] Billet, Matthew T., Mark J. Flannery, and Jon A. Garfinkel, 1995, "The Effect of Lender Identity on a Borrowing Firm's Equity Return," Journal of Finance 50, 699-718.

[6] Boyd, John, and Edward C. Prescott, 1986, "Financial Intermediary-Coalitions," Journal of Economic Theory 38, 211-232.

[7] Cantillo, Miguel, and Julian Wright, 2000, How Do Firms Choose Their Lenders? An Empirical Investigation," Review of Financial Studies 13, 155-189.

[8] Datta, Sudip, Mai Iskandar-Datta, and Ajay Patel, 2000, "Some Evidence on the Uniqueness of Initial Public Debt Offerings," Journal of Finance 55, 715-743.

[9] Detragiache, Enrica, 1994, "Public versus Private Borrowing: A Theory with Implications for Bankruptcy Reform," Journal of Financial Intermediation 3, $327-54$. 
[10] Diamond, Douglas W., 1984, "Financial Intermediation and Delegated Monitoring," Review of Economic Studies 51, 393-414.

[11] Diamond, Douglas W., 1991, "Monitoring and Reputation: The Choice between Bank Loans and Directly Placed Debt," Journal of Political Economy 99, 689721.

[12] Diamond, Douglas W., 1993, "Seniority and Maturity of Debt Contracts," Journal of Financial Economics 33, 341-368.

[13] Gilson, Stuart C., and Jerold B. Warner, 1997, "Junk Bonds, Bank Debt, and Financing Corporate Growth," mimeograph.

[14] Gorton, Gary and James Kahn, 2000, "The Design of Bank Loan Contracts," Review of Financial Studies 13, 331-64.

[15] Grinblatt, Mark and Sheridan Titman, 1998, Financial Markets and Corporate Strategy, Irwin/McGraw-Hill, New York.

[16] Hadlock, Charles, and Christopher James, 2000, "Bank Lending and the Menu of Financing Options," mimeograph.

[17] Holmstrom, Bengt, and Jean Tirole, 1997, "Financial Intermediation, Loanable Funds, and the Real Sector," Quarterly Journal of Economics 112, 663-692.

[18] James, Christopher, 1987, "Some Evidence on the Uniqueness of Bank Loans," Journal of Financial Economics 19, 217-235.

[19] Krishnaswami, Sudha, Spindt, Paul A., and Venkat Subramaniam, 1999, "Information Asymmetry, Monitoring, and the Placement Structure of Corporate Debt," Journal of Financial Economics 51, 407-34. 
[20] Lummer, Scott, and John McConnell, 1989, "Further Evidence on the Bank Lending Process and the Capital Market Response to Bank Loan Agreements," Journal of Financial Economics 25, 99-122.

[21] Myerson, Roger, 1979, "Incentive Compatibility and the Bargaining Problem," Econometrica 47, 61-74.

[22] Novaes, Walter and Luigi Zingales, 1995, "Capital Structure Choice when Managers Are in Control: Entrenchment versus Efficiency," mimeograph.

[23] Rajan, Raghuram G., 1992, "Insiders and Outsiders: The Choice between Informed and Arm's-Length Debt," Journal of Finance 47, 1367-1400.

[24] Repullo, Rafael, and Javier Suarez, 1998, "Monitoring, Liquidation, and Security Design," Review of Financial Studies 11, 163-188.

[25] Sappington, David, 1983, "Limited Liability Contracts between Principal and Agent," Journal of Economic Theory 29, 1-21.

[26] Slovin, Myron B., Shane A. Johnson, and John L. Glascock, 1992, "Firm Size and the Information Content of Bank Loan Announcements," Journal of Banking and Finance 16, 1057-1071.

[27] Smith, Clifford W. Jr., and Jerold Warner (1979), "On Financial Contracting: An Analysis of Bond Covenants", Journal of Financial Economics 7, 117-161.

[28] Wruck, Karen H., 1989, "Equity Ownership Concentration and Firm Value: Evidence from Private Equity Financings," Journal of Financial Economics 23, $3-28$.

[29] Zwiebel, Jeffrey, 1996, "Dynamic Capital Structure under Managerial Entrenchment," American Economic Review 86, 1197-1238. 